Supporting Information

\title{
Polydirectional Microvibration Energy Collection for Self-Powered Multifunctional Systems Based on Hybridized Nanogenerators
}

Hongmei Yang ${ }^{\mathrm{a}, 1}$, Mingming Denga, ${ }^{\mathrm{a}, 1}$, Qixuan Zeng ${ }^{\mathrm{a}}$, Xuemei Zhang ${ }^{a}$, Jie Hu ${ }^{\mathrm{a}}$, Qian Tang $^{\mathrm{a}}$, Huake Yang ${ }^{\mathrm{a}}$, Chenguo $\mathrm{Hu}^{\mathrm{a}}$, Yi Xi ${ }^{\mathrm{a}, \mathrm{b}^{*}}$, Zhong Lin Wang ${ }^{\mathrm{b} *}$

${ }^{a}$ State Key Laboratory of Power Transmission Equipment \& System Security and New Technology, Department of Applied Physics, School of Chemistry and Chemical Engineering, Chongqing University, Chongqing, 400044, China

${ }^{b}$ Beijing Institute of Nanoenergy and Nanosystems, Chinese Academy of Sciences Beijing, 100083, China

${ }^{1}$ These authors contributed equally to this work

* Corresponding authors at: yxi6@cqu.edu.cn, zhong.wang@mse.gatech.edu

\section{Contents:}

Figure S1. Optimization of one layered TENG.

Figure S2. Electric output performance of TENG part.

Figure S3. Electric output performance of EMG part.

Figure S4. Schematic diagram of logic circuit.

Figure S5. Schematic illustrations of working mechanism and charge distribution of the amplitude of vibration sensor.

Table S1. A comparison table of the output performance of TEHG with the other devices already reported.

Movie S1. LED arrays powered by the device by minor water wave.

Movie S2. Self-powered sea water splitting system.

Movie S3. Self-powered vibration amplitude sensor system based on LabVIEW software. 

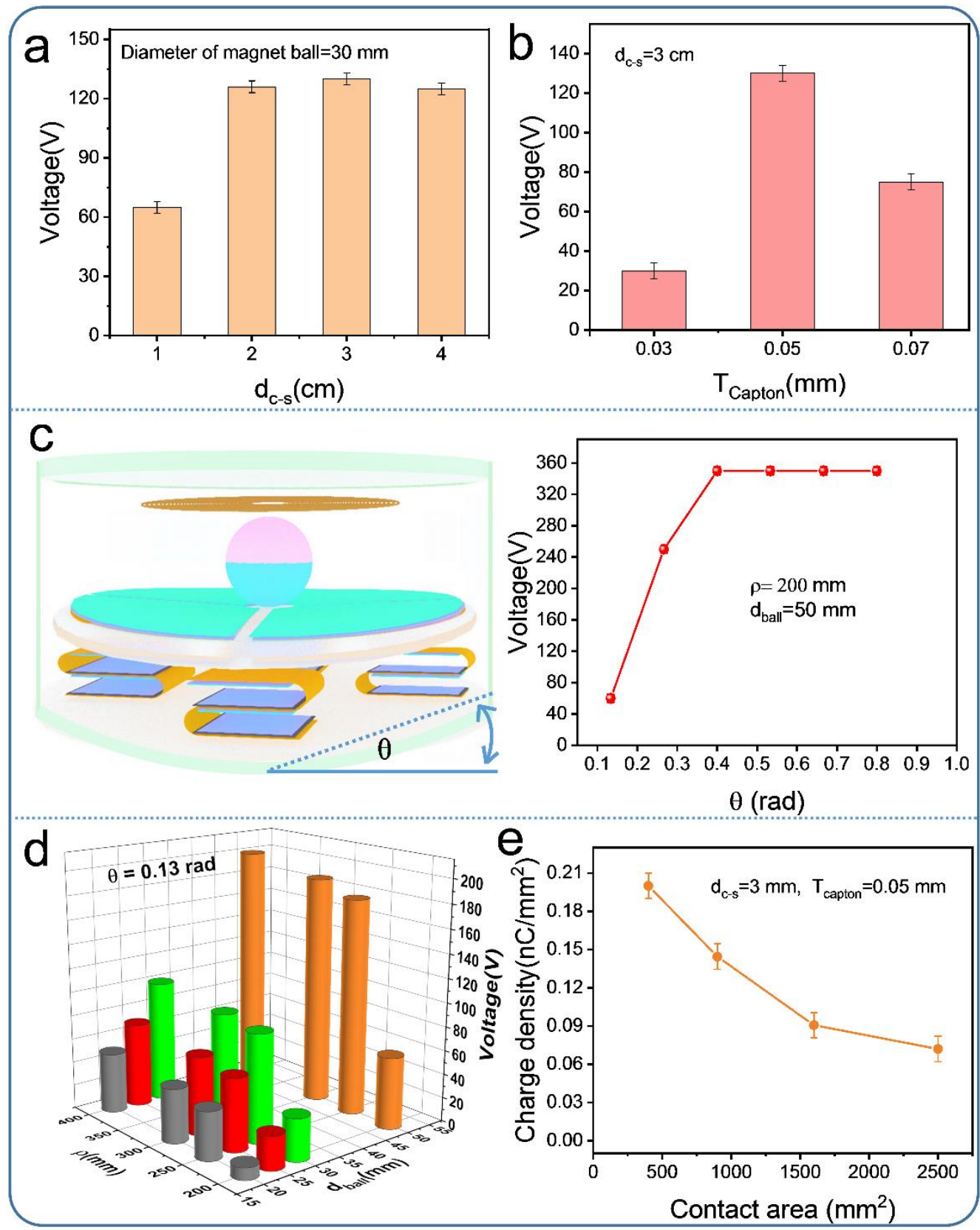

Figure S1. Optimization of one layered TENG. (a) Voltage $v s . \mathrm{d}_{\mathrm{c}-\mathrm{s}}$ (b) Voltage $v s . \mathrm{T}_{\text {Capton }}$.

(c) Voltage vs. $\theta$ (left part is the schematic illustration of radian of vibration $(\theta)$ ). (d)

Voltage $v s . \rho$ and $\mathrm{d}_{\text {ball. }}$ (e) Charge density vs. contact area. 


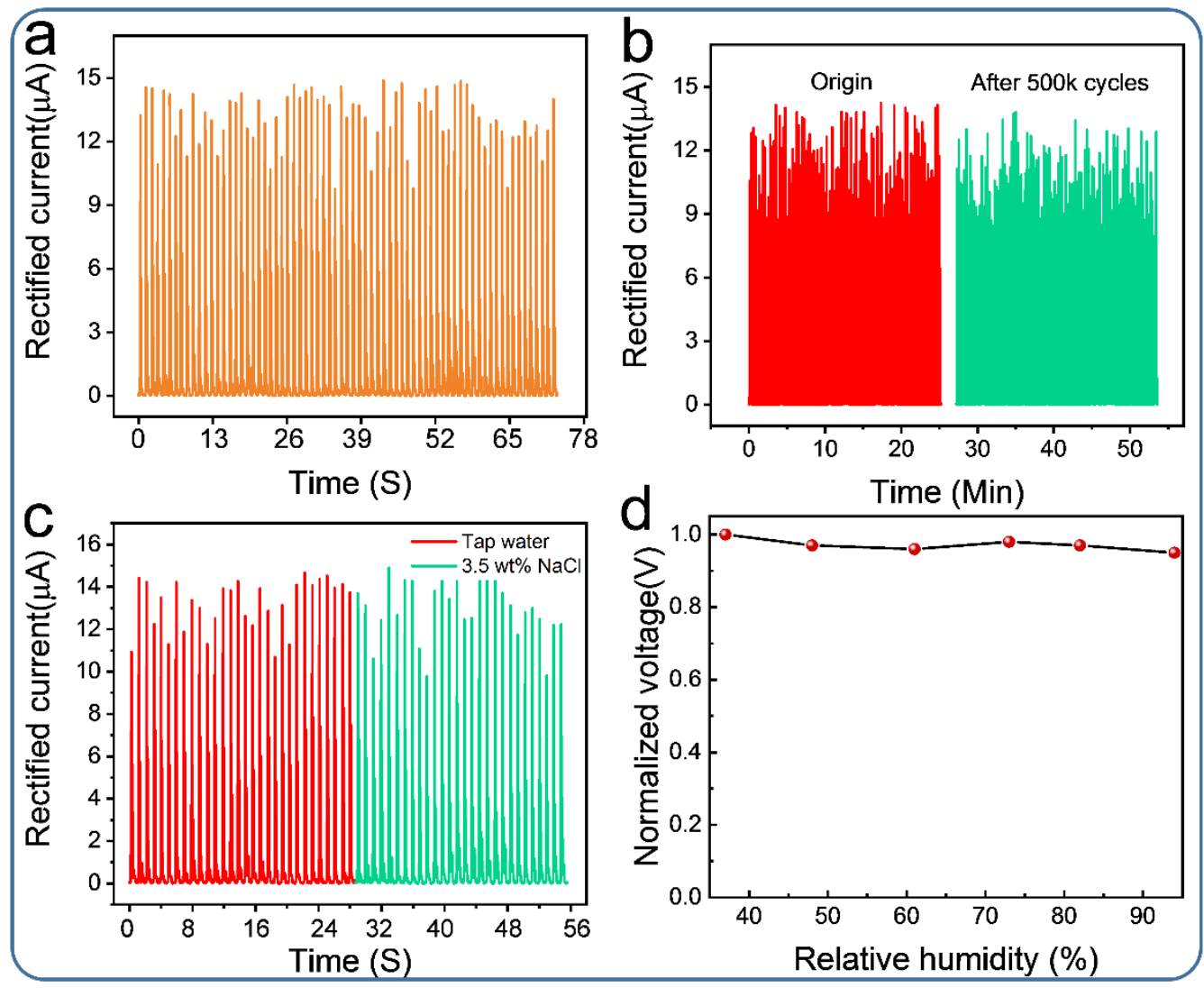

Figure S2. Electric output performance of TENG part. (a) Rectified $\mathrm{I}_{\mathrm{sc}}$ driven by minor water wave. (b) Robustness testing. (c) Rectified $\mathrm{I}_{\mathrm{sc}}$ with different solutions. (d) Normalized voltage $v s$. relative humidity with tap water. 


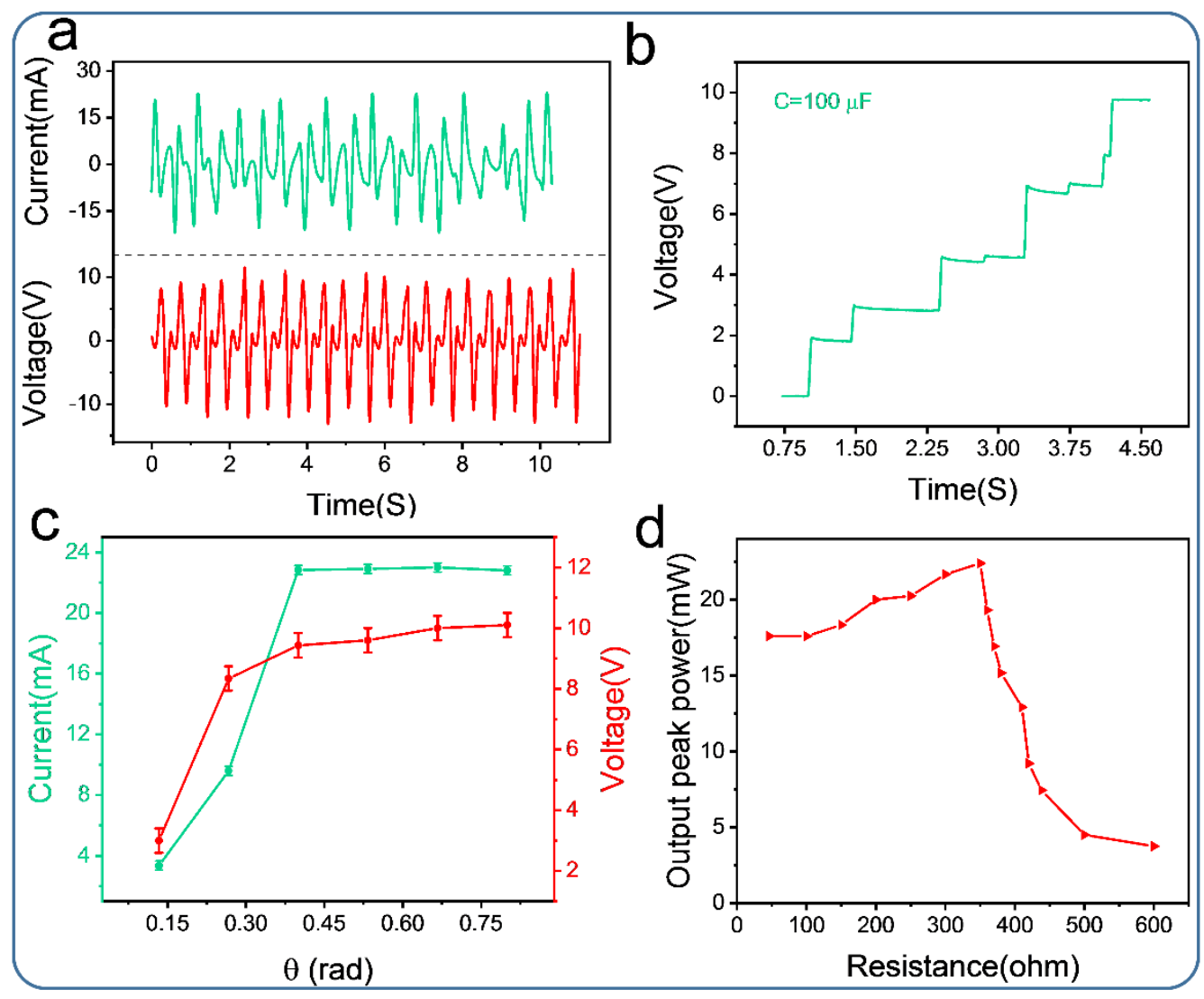

Figure S3. Electric output performance of EMG part. (a) $\mathrm{I}_{\mathrm{sc}}, \mathrm{V}_{\mathrm{oc}}$ driven by minor water wave. (b) Measured voltages of a $100 \mu \mathrm{F}$ capacitor charged by EMG by minor water wave. (c) $\mathrm{I}_{\mathrm{sc}}$ and $\mathrm{V}_{\mathrm{oc}} v s . \theta(\mathrm{f}=1 \mathrm{~Hz}$, driven by a Microstep Driver). (d) Dependence of average peak power on the resistance of the external load $(\mathrm{f}=1 \mathrm{~Hz}$, $\theta=0.4 \mathrm{rad}$, driven by a Microstep Driver). 

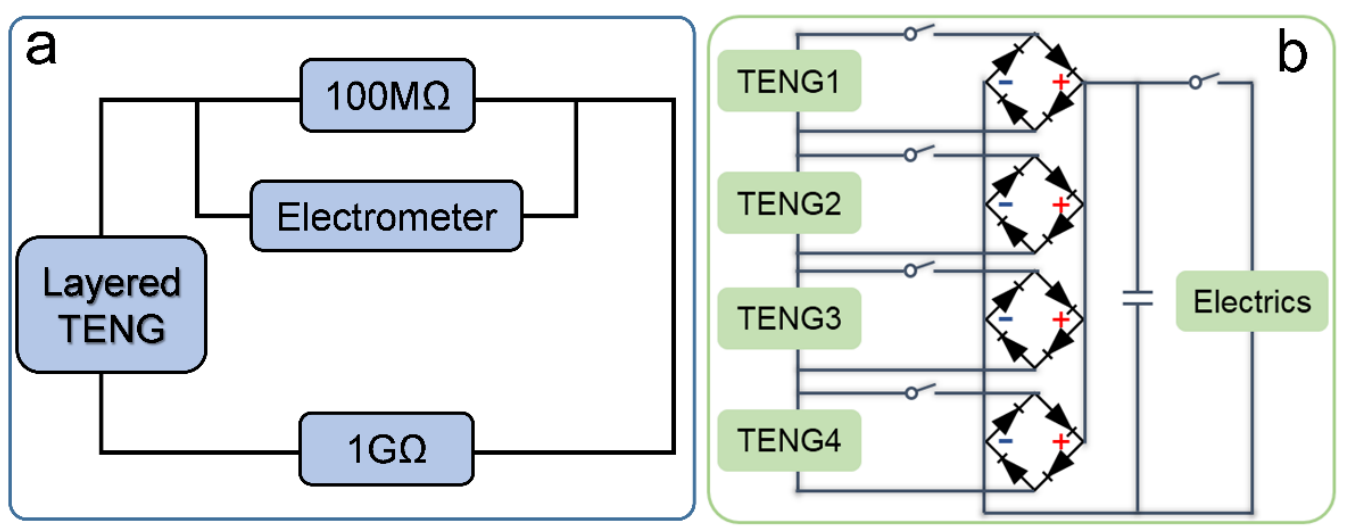

Figure S4. Schematic diagram of logic circuit. (a) Voltage measurement of multilayered TENG. (b) Configurations of basic zigzag multilayered TENG units. 


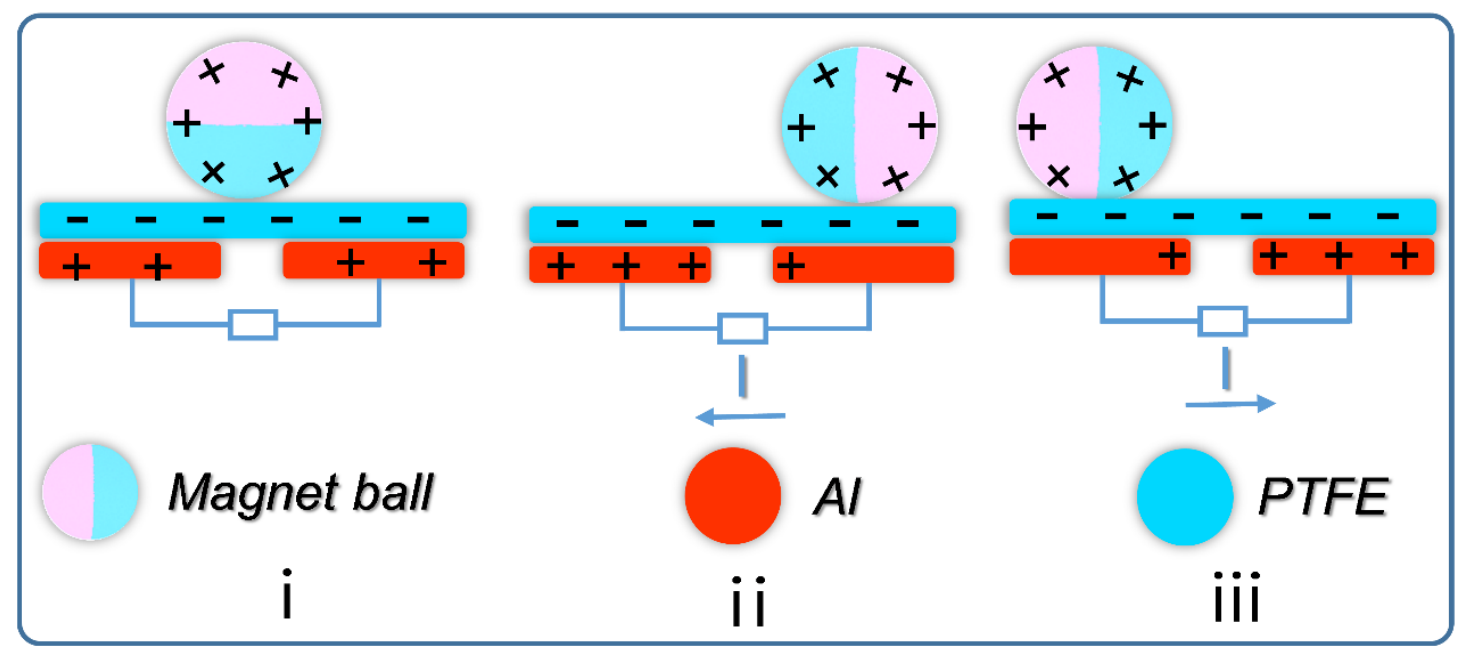

Figure S5. Schematic illustrations of working mechanism and charge distribution of the amplitude of vibration sensor. 


\begin{tabular}{|c|c|c|c|c|c|c|c|}
\hline $\begin{array}{c}\text { Working } \\
\text { frequency }\end{array}$ & $100 \mathrm{~Hz}$ & $30 \mathrm{~Hz}$ & $8.5 \mathrm{~Hz}$ & $3.7 \mathrm{~Hz}$ & $1.1 \mathrm{~Hz}$ & $1 \mathrm{~Hz}$ \\
\hline $\begin{array}{c}\text { Output } \\
\text { power }\end{array}$ & $0.4 \mathrm{~W} / \mathrm{m}^{2}$ & $2.76 \mathrm{~W} / \mathrm{m}^{2}$ & $0.045 \mathrm{~W} / \mathrm{m}^{2}$ & $0.252 \mathrm{~W} / \mathrm{m}^{2}$ & $2.04 \mathrm{~W} / \mathrm{m}^{3}$ & $0.76 \mathrm{~W} / \mathrm{m}^{2}$ \\
\hline & & & & & & & \\
\hline
\end{tabular}

Table S1. A comparison table of the output performance of TEHG with the other devices already reported. 